\title{
Refractory Anaplastic Ependymoma
}

National Cancer Institute

\section{Source}

National Cancer Institute. Refractory Anaplastic Ependymoma. NCI Thesaurus. Code C160913.

Anaplastic ependymoma that is resistant to treatment. 